\title{
Business Group Management in Japan
}


Monden Institute of Management: Japanese Management and

Editor-in-Chief: Yasuhiro Monden (Mejiro University, Japan)

\section{Published}

Vol. 1 Value-Based Management of the Rising Sun edited by Yasuhiro Monden, Kanji Miyamoto, Kazuki Hamada, Gunyung Lee \& Takayuki Asada

Vol. 2 Japanese Management Accounting Today edited by Yasuhiro Monden, Masanobu Kosuga, Yoshiyuki Nagasaka, Shufuku Hiraoka \& Noriko Hoshi

Vol. 3 Japanese Project Management:

KPM - Innovation, Development and Improvement edited by Shigenobu Ohara \& Takayuki Asada

Vol. 4 International Management Accounting in Japan: Current Status of Electronics Companies edited by Kanji Miyamoto

Vol. 5 Business Process Management of Japanese and Korean Companies edited by Gunyung Lee, Masanobu Kosuga, Yoshiyuki Nagasaka \& Byungkyu Sohn

Vol. 6 M\&A for Value Creation in Japan edited by Yasuyoshi Kurokawa

Vol. 7 Business Group Management in Japan edited by Kazuki Hamada 


\title{
Business Group Management in Japan
}

editor

\author{
Kazuki Hamada \\ Kwansei Gakuin University, Japan
}


Published by

World Scientific Publishing Co. Pte. Ltd.

5 Toh Tuck Link, Singapore 596224

USA office: 27 Warren Street, Suite 401-402, Hackensack, NJ 07601

UK office: 57 Shelton Street, Covent Garden, London WC2H 9HE

\section{British Library Cataloguing-in-Publication Data}

A catalogue record for this book is available from the British Library.

\section{BUSINESS GROUP MANAGEMENT IN JAPAN Monden Institute of Management: Japanese Management and International Studies — Vol. 7 Copyright (C) 2010 by World Scientific Publishing Co. Pte. Ltd. \\ All rights reserved. This book, or parts thereof, may not be reproduced in any form or by any means, electronic or mechanical, including photocopying, recording or any information storage and retrieval system now known or to be invented, without written permission from the Publisher.}

For photocopying of material in this volume, please pay a copying fee through the Copyright Clearance Center, Inc., 222 Rosewood Drive, Danvers, MA 01923, USA. In this case permission to photocopy is not required from the publisher.

ISBN-13 978-981-4289-50-4

Printed in Singapore. 


\title{
Japan Society of Organization and Accounting
}

\author{
President \\ Kazuki Hamada, Kwansei Gakuin University, Japan \\ Vice Presidents \\ Gunyung Lee, Niigata University, Japan \\ Kanji Miyamoto, Osaka Gakuin University, Japan
}

\section{Directors}

Henry Aigbedo, Oakland University, USA

Shufuku Hiraoka, Soka University; Japan

Mahfuzul Hoque, University of Dhaka, Bangladesh

Noriko Hoshi, Hakuoh University, Japan

Tomonori Inooka, Kokushikan University, Japan

Chao Hsiung Lee, National Chung Hsing University, Taiwan

Yoshiyuki Nagasaka, Konan University, Japan

\section{Founder 83 Editor-in-Chief}

Japanese Management and International Studies

Yasuhiro Monden, Mejiro University, Japan

\section{Mission of JSOA and Editorial Information}

For the purpose of making a contribution to the business and academic communities, the Japan Society of Organization and Accounting (JSOA), a reformed and expanded organization from the Monden Institute of Management, is committed to publishing the book series, entitled Japanese Management and International Studies, with a refereed system.

Focusing on Japan and Japan-related issues, the series is designed to inform the world about research outcomes of the new "Japanese style management system" developed in Japan. It includes the Japanese version of management systems developed abroad. In addition, it publishes research by foreign scholars and concerning foreign systems that constitute significant points of comparison with the Japanese system. 
Research topics included in this series are management of organizations in a broad sense (including the business group) and the accounting that supports the organization. More specifically, topics include business strategy, organizational restructuring, corporate finance, M\&A, environmental management, business models, operations management, managerial accounting, financial accounting for organizational restructuring, manager performance evaluation, remuneration systems, and management of revenues and costs. The research approach is interdisciplinary, which includes case studies, theoretical studies, normative studies and empirical studies, but emphasizes real world business.

Each volume contains the series title and a book title which reflects the volume's special theme.

Our JSOA's board of directors has established an editorial board of international standing, which is served by the Monden Institute of Management. In each volume, guest editors who are experts on the volume's special theme serve as the volume editors. 


\title{
Editorial Board
}

\author{
MONDEN INSTITUTE OF MANAGEMENT \\ Japanese Management and International Studies
}

Editor-in-Chief

Yasuhiro Monden, Mejiro University, Japan

Managing Editors

Henry Aigbedo, Oakland University, USA

Kazuki Hamada, Kwansei Gakuin University, Japan

Shufuku Hiraoka, Soka University; Japan

Mahfuzul Hoque, University of Dhaka, Bangladesh

Noriko Hoshi, Hakuoh University, Japan

Tomonori Inooka, Kokushikan University, Japan

Chao Hsiung Lee, National Chung Hsing University, Taiwan

Gunyung Lee, Niigata University, Japan

Yoshiyuki Nagasaka, Konan University, Japan

\section{Editorial Advisory Board}

Mohammad Aghdassi, Tarbiat Modarres University, Iran

Mahmuda Akter, University of Dhaka, Bangladesh

Takayuki Asada, Osaka University, Japan

Takahiro Fujimoto, University of Tokyo, Japan

Péter Horváth, University Stuttgart, Germany

Arnd Huchzermeier, WHU Koblenz, Germany

Christer Karlsson, Copenhagen Business School, Denmark

Masanobu Kosuga, Kwansei Gakuin University, Japan

Bruce Henry Lambert, Stockholm School of Entrepreneurship, Sweden

Rolf G Larsson, Lund University, Sweden

John Y. Lee, Pace University, USA

Jose Antonio Dominguez Machuca, University of Sevilla, Spain

Kenneth A. Merchant, University of Southern California, USA

Yoshiteru Minagawa, Nagoya Gakuin University, Japan

Kanji Miyamoto, Osaka Gakuin University, Japan 
Tengku Akbar Tengku Abdullah, Universiti Kebangsaan Malaysia, Malaysia

Jimmy Y.T. Tsay, National Taiwan University, Taiwan

Susumu Ueno, Konan University, Japan

Eri Yokota, Keio University, Japan

Walid Zaramdini, Al Akhawayn University, Morocco 


\section{Contents}

Preface xiii

About the Volume Editor xix

List of Contributors $\quad$ xxi

Part 1: Accounting Information for Group Management and Management Control System

Management Accounting Information for Consolidated

Group Management

Kazuki Hamada

Management Control Systems of Japanese Pure

Holding Companies

Makoto Tomo, Makoto Yori and Takayuki Asada

\section{Part 2: M\&A Including MBO and Outsourcing for Group Reformation}

Influence of M\&A on Financial Performance: Measuring

the Performance of M\&A from Sustainability of Utility

Kozo Suzuki

Management Buyout of a Japanese Business Group

Naoyuki Kaneda

Managerial Significance of Strategic Outsourcing

Shunzo Matsuoka

Acquisition Price as an Incentive Price of M\&A

Yasuhiro Monden 
Part 3: Analysis of Accounting Information for Consolidated and Business Group and Segmental Business Units

Consolidated Accounting Information for Business Group

Management

Manabu Takano

Business Evaluation of a Company Group in Japan:

A Case Study of Segment Reporting by Panasonic

Electric Works

Shufuku Hiraoka

\section{Part 4: Management of Inter-Firm Relations}

How Can Management Accounting Achieve Goal Congruence Among Supply Chain Partners?

Yoshiteru Minagawa

How to Maintain the Bargaining Position Defined

in Toyota's Dealership Control

Hiroshi Ozawa

Royalties and Profit Sharing: Focusing on Seven-Eleven

Japan Co., Ltd.

Noriko Hoshi

Factors Influencing Control Mechanisms in Joint Ventures:

Evidence from Japanese

Manufacturing Industries

Yuichi Kubota

Does Inter-Firm Cooperation Contribute to the Performance of Japanese Firms?

Junya Sakaguchi

Concept of Incentive Price for Motivating Inter-Firm

Cooperation

Yasuhiro Monden 


\section{Part 5: Inter-Organizational Learning and Autonomous} Organizations

Management of Population-level Learning and Inter-

Organizational Relations in Japan

Hiroki Kondo

Management Control System in an Empowered Organization

Katsuhiro Ito

Index 
This page intentionally left blank 


\section{Preface}

Currently, Japanese companies are positively promoting the "integration and/or separation of businesses" with the aim of gaining a competitive advantage. Although various individual and combined business models exist, the common goal is to enhance the value of the business.

Nowadays, the competition that exists among business groups is more important than that among individual firms. Therefore, the strategies for managing numerous individual firms have become important from the viewpoint of the business group as a whole.

In Japan, there are many core companies that engage in unique interfirm relationships, called "Keiretsu", which confer substantial influence upon the members of the group through continuous transactions, even in the absence of capital-alliances. Therefore, our research also considers these uniquely Japanese attributes. The management methods employed in Japanese companies include the following: (1) application of evaluation systems; (2) execution of mergers and acquisitions (M\&A); (3) utilization of segment information; (4) management of inter-firm relations; and (5) adoption of organizational learning.

In this book, we explore and elucidate business group management (BGM) and inter-firm management in Japanese companies, both theoretically and practically through case studies, survey research, and other methodologies. The analyses, hypotheses, and conclusions presented in this book will be useful for business practitioners and for academic researchers.

This book consists of the following five parts.

\section{Part 1: Accounting Information for Group Management and Management Control Systems}

The first paper by Hamada examines the managerial accounting methods used in business group management by analyzing the role played by the 
group headquarters. In particular, it is examined how the managerial accounting system and consolidated performance evaluation system are designed and utilized in Japanese companies.

The second paper by Tomo, Yori, and Asada investigates the current situation and problems associated with the application of management control systems in companies that are falling under the control of holding company. The meaning of business reformation, the extent of authority delegation, and the roles of the holding company are examined.

\section{Part 2: M\&A, Including MBO, and Outsourcing for Group Reformation}

The first paper by Suzuki investigates the effects of M\&A on financial performance. This paper regards M\&A as a means to transfer business resources from one company to another, whereby a firm or business is itself a type of resource. From this standpoint, the effects of M\&A on business sustainability performance are evaluated.

The second paper by Kaneda examines management buyouts (MBOs) of Japanese companies. In MBOs, corporations tend to retain the original management and employees, generally avoiding massive layoffs. Thus, some large corporations prefer to use MBOs to spin off subsidiaries. As an example, the spinning off of subsidiaries from Nissan Motor Company, during which the management changed its style of corporate management, is presented.

The third paper by Matsuoka discusses outsourcing. The purpose of outsourcing has evolved, and strategic outsourcing or value-creation outsourcing has emerged in recent years. This paper describes the historical transitions undergone by outsourcing and looks in particular at the current managerial meaning of strategic outsourcing.

The fourth paper by Monden explains the acquisition price of M\&A as a practical example of the incentive price, using the case study of the merger between City group and Nikko. The estimated synergy of M\&A will be allocated to both the acquiring firm and the acquired firm. The central problem in this allocation is how to determine the acquisition premium for the stockholders of the acquired firm considering the interest of stockholders of the acquiring firm. 


\section{Part 3: Analyses of Accounting Information for Consolidated Business Groups and Segmental Business Units}

The first paper by Takano discusses how management accounting information is used for BGM through the analysis of consolidated accounting information. The associated analyses with case studies are provided in this paper.

The second chapter by Hiraoka investigates segment reporting for business evaluation using a case study. Starting in April 2010, Japanese companies will be obliged to introduce a "management approach" to segment reporting. However, Panasonic Electric Works is already applying this approach to arrangement. Through a case study of segment reporting at Panasonic Electric Works, this paper shows how an analysis of "business evaluation" can be made.

\section{Part 4: Management of Inter-Firm Relations}

The first paper by Minagawa discusses how management accounting can achieve the goal congruence among supply chain partners. Among the critical issues to be resolved for efficient supply chain management is how to reduce the risks that associate with opportunistic behaviors by partners.

The second paper by Ozawa demonstrates the hypothesis that for Toyota to maintain its strong negotiating position, it is necessary to have a system in place that rewards dealerships based on their sales performances, rather than one that increases sales by reducing invoice prices in the low-demand season.

The third paper by Hoshi discusses the royalties of franchise contracts and profit allocation. The basis for assessing royalties in a franchise contract in a convenience store business is usually the gross profit or the gross profit plus the "loss amount," which corresponds to the cost of purchased merchandise that was subsequently discarded because it was past its consumption-date. This paper examines the effect of loss inclusion in the royalty base, so that the profit allocation issues that arise in a convenience store business can be clarified.

The fourth paper by Kubota investigates the factors that influence the control mechanisms of joint ventures. The success of inter-company 
alliances or joint ventures is dependent upon the management control systems for inter-firm relations. In general, compared to the situation in Western companies, the managers of Japanese companies are inclined to get involved in on-site, shop-floor-level manufacturing, and to conduct informal controls. This paper clarifies the Japanese inter-firm control mechanism through the research survey of the top management of manufacturing companies in Japan.

The fifth paper by Sakaguchi explores the question as to whether or not inter-firm cooperation contributes to the performance level of Japanese firms, based on a survey of 97 Japanese manufacturing companies. Inter-firm cooperation, the relationship between cooperation and performance, and the emerging problems in Japanese inter-firm cooperation are examined.

The sixth paper by Monden discusses incentive price used as a transaction price for allocating the joint profits to the member firms of the network organization. The criterion to determine such an incentive price is the contribution grade of how each party has contributed to gain the joint profit, and it will be measured based on the tangible and/or intangible assets or the expenses paid to develop such assets.

\section{Part 5: Inter-Organizational Learning and Autonomous Organizations}

The first paper by Kondo discusses the management of population-level learning and inter-organizational relations in Japan. In this paper, the differences in the various learning patterns of various inter-firm relations are summarized. In addition, appropriate organizational learning strategies to be adopted by each organization to adapt flexibly to changes in the management environments, while controlling dysfunctional results, are discussed.

The second paper by Ito investigates management control systems for empowered organizations. The concepts and principles of empowered organizations contrast with those of centralized organizations, which are designed and managed using a "command-and-control" logic. The relationship between the organization principle and management accounting is analyzed in detail. Tentative conclusions are reached based on case studies of high-achieving Japanese companies, such as Toyota, Kyocera, Kao, and 7-Eleven. 
I am very grateful to Ms. Juliet Lee Ley Chin, the Social Sciences commissioning editor of World Scientific Publishing Company, for her invaluable efforts in making this book a reality. Furthermore, Ms. Kim Tan, the book editor, is acknowledged for her handling of the manuscripts. Lastly, I would like to express my special thanks to Prof. Yasuhiro Monden, founder of the Monden Institute of Management, who made it possible for me to publish this book as a book series (Vol. 7) of the Institute.

Kazuki Hamada 25 April 2009 
This page intentionally left blank 


\title{
About the Volume Editor
}

\author{
Kazuki Hamada \\ Professor of Institute of Business and Accounting, \\ Kwansei Gakuin University \\ 1-155 Uegahara-1bancho, Nishinomiya, Hyogo 662-8501, Japan \\ President, Japan Society of Organization and Accounting \\ Majoring in Management Accounting \\ BA and MBA from Kwansei Gakuin University, \\ Ph.D. from Tsukuba University \\ k-hamada@kwansei.ac.jp
}

\section{Main publications}

"Total Productivity Management and the Theory of Constraints: An Integrated Application of Supply Chain Management Methods," in Monden, Y. et al., eds., Japanese Management Accounting Today, World Scientific, 2007.

"Managerial Roles of Financial and Non-Financial Measures in Supply Chain and Engineering Chain Management," in Monden, Y. et al., eds., Value-Based Management of the Rising Sun, World Scientific, 2006, Chapter 23.

"A Method for Simultaneously Achieving Cost Reduction and Quality Improvement," "A Management System for the Simultaneous Attainment of Customer Satisfaction and Employee Satisfaction," in Monden, Y., ed., Japanese Cost Management, Imperial College Press, 2000, Chapter 7 and Chapter 19.

Evolution of Management Accounting Method, Chuoukeizai-sha, 1998 (in Japanese).

"Target Costing and Kaizen Costing in the Japanese Automobile Companies," Journal of Management Accounting Research, Vol. 3, 1992 (co-authored with Monden, Y.). 
This page intentionally left blank 


\title{
List of Contributors
}

\author{
Takayuki Asada \\ Professor, Graduate School of Economics, Osaka University \\ 1-7 Machikaneyama, Toyonaka, Osaka 560-0043, Japan \\ Ph.D. from Kobe University \\ asada@econ.osaka-u.ac.jp
}

\section{Shufuku Hiraoka}

Professor, Faculty of Business Administration, Soka University

1-236 Tangi-cho, Hachioji, Tokyo 192-0087, Japan

Ph.D. from Meiji University

shiraoka@soka.ac.jp

\section{Noriko Hoshi}

Professor, Faculty of Business Adminstration, Hakuoh University 1117 Daigyoji, Oyama, Tochigi 323-8588, Japan

Ph.D. from Tsukuba University

\section{Katsuhiro Ito}

Professor, Faculty of Economics, Seikei University

3-3-1 Kichijyoji-kitamachi, Musashino, Tokyo 180-8633, Japan

MBA from Hitotsubashi University

kito@econ.seikei.ac.jp

\section{Naoyuki Kaneda}

Professor, Faculty of Economics, Gakushuin University

1-5-1 Mejiro, Toshima-ku, Tokyo 171-8588, Japan

Ph.D. from Carnegie Melon University 


\section{Hiroki Kondo}

Lecturer, Faculty of Business Administration, Mejiro University

4-31-1 Nakaochiai, Shinjyuku-ku, Tokyo 161-8539, Japan

Ph.D. from Kyushu University

kondo@mejiro.ac.jp

\section{Yuichi Kubota}

Associate Professor, School of Economics, Osaka Prefecture University 1-1 Gakuen-cho, Naka-ku, Sakai, Osaka 599-8531, Japan

Ph.D. from Kobe University

\section{Syunzo Matuoka}

Professor, Faculty of Business, Hannan University

5-4-33 Amamihigashi, Matubara, Osaka 580-8502, Japan

MBA from Osaka Prefecture University

\section{Yoshiteru Minagawa}

Professor, Faculty of Commerce, Nagoya Gakuin University

1-25 Atsuta, Nishimachi, Atsuta, Nagoya, Aichi 456-8612, Japan

Ph.D. from Nagoya University

\section{Yasuhiro Monden}

Professor, Faculty of Business Administration, Mejiro University 4-31-1 Nakaochiai, Shinjyuku-ku, Tokyo 161-8539, Japan

Professor-Emeritus of Tsukuba University

Ph.D. from Tsukuba University

monden@mejiro.ac.jp

\section{Hiroshi Ozawa}

Associate Professor, Graduate School of Economics, Nagoya University Furocho, Chikusa-ku, Nagoya, Aichi 464-8601, Japan

Ph.D. from Nagoya University

\section{Junya Sakaguchi}

Associate Professor, School of Accountancy, Kansai University

3-3-35 Yamate-cho, Suita, Osaka 564-8680, Japan

Ph.D. from Kobe University 


\section{Kozo Suzuki}

Director of Management Section

Tama Waterworks Reform Promotion Center

Tokyo Metropolitan Government

6-7 Midorimati, Tachikawa, Tokyo 190-0014, Japan

Ph.D. from Tsukuba University

\section{Manabu Takano}

Associate Professor, Department of Commerce

Seinan Gakuin University

6-2-92 Nishijin, Sawara-ku, Fukuoka 814-8511, Japan

Ph.D. from Meiji University

\section{Makoto Tomo}

Associate Professor, Faculty of Economics, Seijo University 6-1-20 Seijo, Setagaya-ku, Tokyo 157-8511, Japan

Ph.D. from Osaka University

seijo@xtomo.com

\section{Makoto Yori}

Professor, Graduate School of Accountancy, University of Hyogo

8-2-1 Gakuennishi, Nishi-ku, Kobe, Hyogo 651-2197, Japan

Ph.D. from Kobe University

biwakoshiga@gmail.com 